\title{
The microcirculation in shock
}

\author{
A. L. STALKER
}

From the Department of Pathology, University of Aberdeen

It is right that attention should be directed early in this symposium to the microcirculation in shock for it is at this level of the circulation that we must look for an explanation of this complex and sometimes irreversible clinical condition. The word 'shock' is convenient and firmly established in medical usage but gives no indication of the multifactorial nature of a process probably best defined as loss of microcirculatory control with hypoperfusion. From the consequences of this low flow state stem the clinical and biochemical features of shock.

We know much about the cardiovascular responses to shock at the major circulatory levels but in the microcirculation the changes are more difficult to explain, although relatively simple to describe. The mechanisms for homeostatic adjustment are numerous, interlinked, and far from completely established; they are well reviewed in 'Microcirculation as related to shock' (Shepro and Fulton, 1968). It is impossible in this communication to review the subject comprehensively, and I shall, therefore, give a short account of microcirculatory techniques and the normal microcirculation, indicate the main changes seen in shock, and select a few topics of current importance and interest.

\section{Methods for Study of the Microcirculation}

Microcirculatory methods abound-and there is still ample scope for ingenuity in devising further techniques. A résumé of existing methods will not be attempted here. The British Microcirculation Society, formed in 1963, exists to promote awareness of the techniques and hence their further use and improvement: a useful introduction, with bibliography, to some of the more commonly used methods will be found in the Society's 'Techniques used in the study $\overrightarrow{\text { of }}$ microcirculation' (Chambers and Monro, 1969\% A note on the problems encountered in this fiefi is, however, necessary.

In man the magnification achieved by the available methods of study (nail-fold, skin capid lary, retinal and conjunctival microscopy) is inadequate for the visualization of individua blood cells that is a prerequisite for analysis off flow in capillaries (Stalker, 1964). High magnificar tion recordings have, however, recently been made in the transilluminated human omentum (Bond, Guest, and Derrick, 1968), and Bråne mark (1966), using special titanium chambers inserted into the arms of volunteers, has obtaine excellent records of capillary flow. Inevitably foi: high magnification work one has to turn to the experimental animal and a bewildering range of techniques. The main problems here include species and organ variations in flow patterns; individual variations in vasomotor activity; the ever-present risk that injury, however trivias during preparation of the tissue or organ wit affect the observations; the impossibility as y. of identifying and recording random sequentiab events occurring at different areas of a large vascular field; the difficulty in seeing deeply int the vasculature of a solid organ; and the need ffor extensive ciné recording, much of it at speeds 200 pictures per second or faster. Because of these limitations much of the literature on micre circulation is still descriptive and accurafe measurement is often impossible.

An obvious advantage of the microcirculato approach is its very dynamism. It can transform concepts based solely on study of tissue morpho\& ogy. A further benefit is its ready correlation with ultrastructural studies: the well known illus trations of leucocyte emigration (Florey an Grant, 1961) are early examples of an approach. that is being increasingly adopted. 


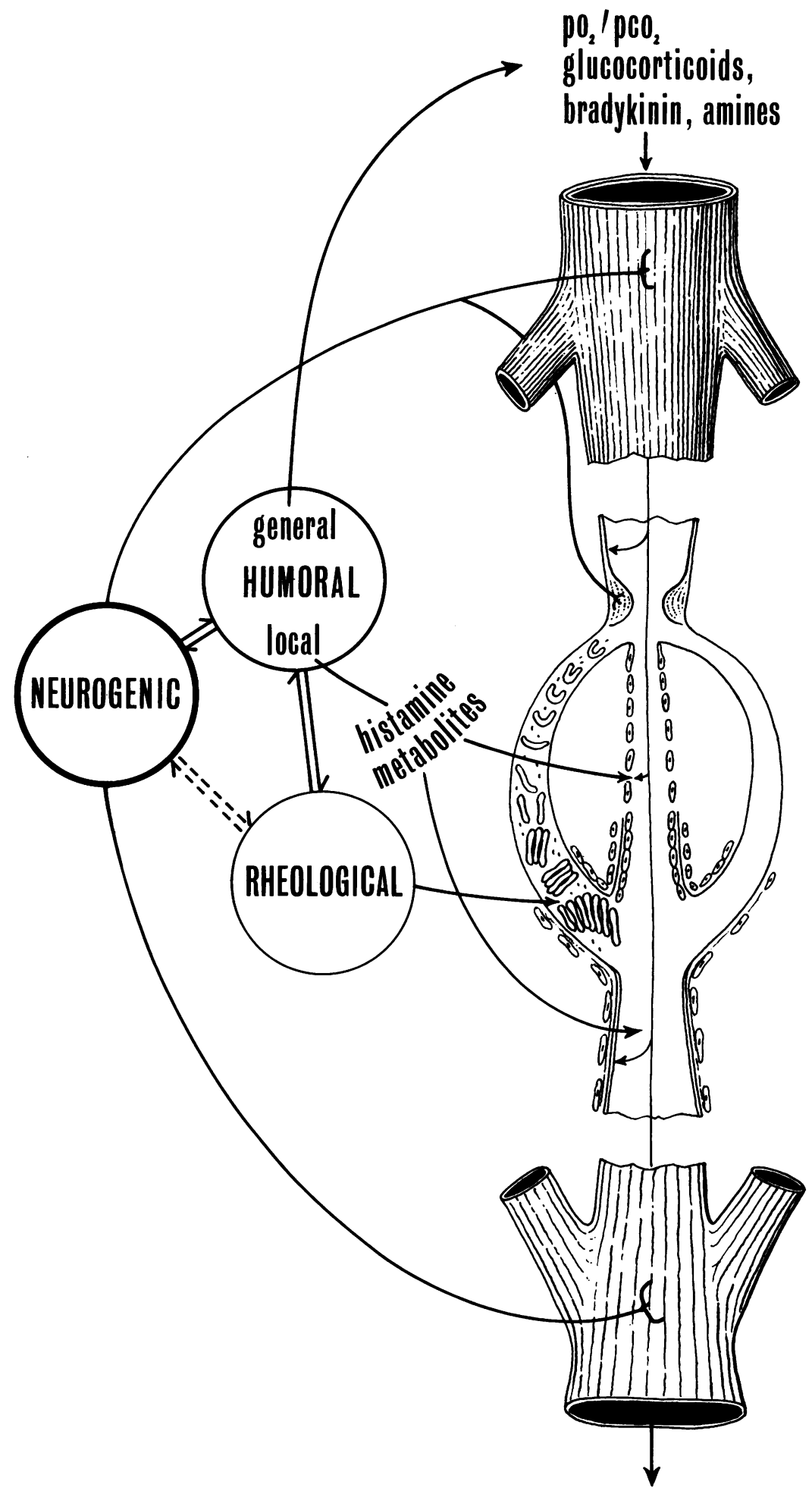

ARTERIOLE

$50-100 \mu$

TERMINAL

ARTERIOLE

$<50 \mu$

PRECAPILLARY

SPHINCTER

7-15 $\mu$

CAPILLARY

to $8 \mu$

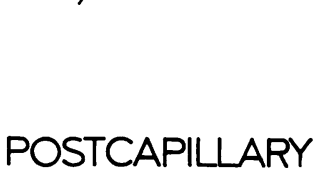

VENULE

8-30 $\mu$

MUSCULAR

VENULES

30-100 $\mu$ 
Most microcirculatory problems are clearly interdisciplinary and will continue to be tackled in the experimental animal, and the choice of species, organ, or tissue, and method is allimportant. Whenever possible results should te confirmed in several species.

\section{The Normal Microcirculation and Its Control}

The detailed anatomy of the microcirculation (Fig.) is still under investigation. A terminology derived from the classical early studies by optical microscopy and the recent careful ultrastructural work of Rhodin $(1967,1968)$ would find reasonable acceptance today. The vessels (with diameters) are, in sequence, arterioles $(50-100 \mu)$, terminal arteriole (less than $50 \mu$ ); precapillary sphincter $(7-15 \mu)$; capillary (up to $8 \mu)$; postcapillary venule $(8-30 \mu)$; collecting and muscular venules $(30-100 \mu)$. Smooth muscle is present in the arteriolar wall and forms a flow-regulating mechanism in the precapillary sphincter; it is absent from capillaries and postcapillary venules but gradually reappears in the larger venules. The arterioles and muscular venules are innervated. The capillaries and postcapillary venules are simple endothelial tubes, capillary fenestration increasing to a maximum at the venous end of the capillary just before the postcapillary venule receives its characteristic additional connective tissue and pericyte support. The micro-architecture of the capillary and postcapillary network is highly variable as is the length of this segment.

Control of the normal microcirculation (Fig.) is of paramount importance in considering the breakdown that occurs in shock. It is neurogenic, humoral, and rheological. Although other possibilities exist, the main certain neurogenic control is effected by a baroreceptor reflex through adrenergic vasoconstrictor nerves supplying arterioles, sphincters, and muscular venules. This response operates at differing intensities in the various regions, and serves, in hypotension, to inaintain cerebral and cardiac flow. The arteriolar and sphincter control mechanisms are especially sensitive to inadequate blood supply. The major part of the peripheral resistance is arteriolar, the sphincters determine the extent of opening of capillary networks, and the venules have a valuable capacitance role. The capillaries and postcapillary venules are best regarded as passive tubes, with maximum permeability at the venous end of the capillary. The concept of active capillary contractility has little to support it and most of the movement that one can observe in a capillary wall seems related to emptying or filling of the tube and not to active changes in the endothelial cell.

Many humoral factors, either circulating generally or, more often, locally produced, are superimposed on and modify this neurogenic control. Examples are hormones, such as gluc $\overline{\overline{0}}$ corticoids, and pharmacologically active agenţ, such, as histamine, bradykinin, and catech lamines. They act either on vasomotor activity or capillary permeability and adjust flow to locat requirements.

Rheological control is best considered together with the changes in shock.

\section{The Microcirculation in Shock}

Whether the cause be haemorrhage, traumge, burns, or other stimulus, the loss of intravasculorr fluid determines a distinct sequence of events $\frac{\text { Th }}{4}$ the experimental animal. There is an immediafe homeostatic vasoconstrictor response wifh arteriolar narrowing, reduction in the number $\overrightarrow{\mathrm{of}}$ open capillaries, and augmented venous retu用 due to venospasm. Tissue anaerobiosis develops. The intensity of this circulatory adaptation varies in different organs; it can be maintained for ondy a limited time.

The arteriolar and precapillary sphincter control fails as a result of hypoxia and the effeet of vasodilating agents circulating generally of more probably, accumulating locally as a result of anaerobic metabolism. Vasomotor paralysis may ensue. The venular channels are less sensiti to hypoxia and, surprisingly, seem to resist $\overline{\mathrm{t}}$ some degree the dilating effect of local metabolites Capillary engorgement follows and flow is sluggish or stagnant; outward movement of flüi occurs; the red cells in the now more concentrated plasma aggregate and the leucocytes marginate and show increased adherence to the endothelium. Blood flow in capillaries, and paxeticularly in postcapillary venules, is at this stage characteristically viscous. This is even mope marked if the shock is of haemoconcentrated type as in burns. Occasionally microthrombus formation, or the passage of small white micreemboli, can be seen in the postcapillary venules.

If this degree of microcirculatory hypoperfusion is treated by fluid replacement these changes can be completely and rapidly reversed If not they worsen and the condition may resist treatment. Masses of aggregated red cells remain trapped in distended capillaries and in posftcapillary venules. The final stage is necrosis of the tissue and its vessels, with haemorrhage. an indication of the well known inability $\&_{f}$ shocked tissues to resist infection, it is of interest to note that ear chambers in shocked rabbits invariably become infected and fall out if tre degree of shock and hypoperfusion has been all severe.

These severe grades of hypoperfusion vary $\underset{\mathrm{m}}{\mathrm{m}}$ the speed of their development in the variogs organs, the vital organs remaining the be perfused for the longest time.

The observation that this severe micror 
circulatory failure cannot invariably be remedied by fluid replacement has led to extensive search for 'toxins' in shock. We must, however, be careful to be sure, before postulating a toxic factor, that physical mechanisms could not equally well explain the facts. The most immediate question for consideration is the altered rheology of the blood. This is an exceedingly complex subject. First, blood is a suspension of deformable cells in a varying fluid protein matrix. Second, in flow through the capillaries there is often deformation of the highly plastic red cells and the inherent viscosity of the red cell content must be taken into account. Third, red cells remain discrete until their flow rate is reduced, but whenever this occurs they tend to aggregate and form simple rouleaux, which in turn can join to form complex aggregates. This aggregation, or sludging, as it has been termed by Knisely, Bloch, Eliot, and Warner (1957), is also dependent on the plasma macromolecular content, and for each colloid there is a critical value above which aggregation occurs (Thorsén and Hint, 1950). The flow of blood is anomalous in respect of its viscosity. At high shear rates (high velocity flow) blood is a Newtonian fluid and behaves like water, but at low shear rates it shows plasticity, ie, its viscosity increases. This increased viscosity at low flow rates is, understandably, further complicated by the aggregation phenomenon, and, in the field of blood viscometry, at the capillary and postcapillary level there is, currently, much debate.

There has long been argument as to whether red cell aggregation is a normal or pathological event. It is seen in capillaries and postcapillary venules where flow is slowest and plasma macromolecular concentrations can be at their highest. It is, in my opinion, best to regard it as a normal event which is generally of slight degree. The small aggregates in a sense may help to regulate capillary flow by a transient obstructive mechanism; capillary filling may in part be determined by the extent of red cell aggregation in the draining venules. When aggregation is severe in the hypoperfusion of shock we can view the picture differently. Complex aggregates are often impacted and trapped in postcapillary venules. The larger venules show a sluggish flow of distinctly granular blood. This can be seen in the conjunctival vessels in man, and it was the classical work of Gelin (1956) in this field that revived interest in blood viscosity. This trapping, or sequestration, of blood cells may persist after correction of blood volume in the experimental animal. I have seen such aggregation break up spontaneously after 48 hours' impaction in a postcapillary venule. On the other hand, the red cells in an aggregate may lose their outlines, fibrin is deposited and a thrombus forms: the process is then irreversible.

It is of importance to know whether or not this severe aggregation is, of itself, harmful. Aggregation can be induced experimentally by the administration of high molecular weight dextrans, and I have found (Stalker, 1967) that aggregation causes micro-infarction which, interestingly enough, is most prominent in the myocardium and liver.

Much research continues in many disciplines on blood viscosity and flow and the last words on red cell aggregation and blood rheology have certainly not been said. It is my present belief that simple aggregation is normal and harmless, if not in fact to some degree regulatory, but that severe aggregation in shock adds a lethal element of capillary obstruction to the low flow state.

Little need be said of the general histopathology of shock. Vascular congestion is nonspecific and the only other feature of note is the occurrence of micro-infarction similar to the lesions described following induced red cell aggregation. It is of some interest that they tend to occur in organs with sinusoidal blood supplies in which flow is normally low, and at the edges or surfaces of organs where the possibility of collateral supply is restricted, eg, the surface of liver and endocardium. It should be remembered that preexisting arterial disease may well intensify hypoperfusion in shock and we are all well aware of the disastrous effects of, say, gastric haemorrhage in patients with atherosclerotic coronary disease.

An occasional finding in fatal shock is fibrin microthrombi in small vessels. This is considered in the next section.

\section{Disseminated Intravascular Coagulation and Endotoxic Shock}

Increasing attention is now being paid to disseminated intravascular coagulation as a possible intermediary mechanism in producing or perpetuating shock (McKay, 1964; Hardaway, 1966). There are now in the literature many reports describing this process and some indicate striking depression of coagulation factors. Fibrin microthrombi can be found in many fatal cases of shock of diverse aetiology; they are often infrequent and haphazardly distributed. Demonstration of their fibrin nature may be difficult as staining methods for fibrin are still not completely satisfactory, and perhaps some pathologists have been too ready to dismiss such microthrombi lightly, forgetting that postmortem fibrinolysis can greatly reduce the amount of deposited fibrin.

The basic concept is that a process of intravascular coagulation of from slow to rapid tempo can be initiated by a wide range of factors. These include certain chemical agents, red cell breakdown products, exemplified by intravascular haemolysis or transfusion of incompatible blood, platelet aggregation and viscous metamorphosis induced by tissue injury or red cell damage, the circulation of particulate material, bacteriaemia 
being a particularly good example, or of antigenantibody complexes, and the entry of thromboplastic material into the circulation from a site of injury. The latter is especially likely to happen when there is haemorrhage and a rise in tissue pressure sufficient to induce parenchymatous embolism (Young and Griffith, 1950). A well known example of this is obstetric accidental haemorrhage which frequently causes hypofibrinogenaemia.

Whenever fibrinogen breakdown products, including fibrin, are formed there will be clearance responses by the fibrinolytic enzyme system and the reticuloendothelial system. The extent to which fibrin is actually deposited on endothelial surfaces will depend upon the balance between the rates of fibrin formation and its clearance. Parallel studies of fibrin degradation products, fibrinolytic activity, and plasma fibrinogen are thus of special value in studying this phenomenon.

It is possible in experimental defibrination to see fibrin deposition in vivo in the microcirculation (Irwin, Chiu, and Nims, 1968; Stalker, Brown, Hall, and Blench, 1969) but the more usual methods for studying disseminated intravascular coagulation are histological, haematological, and ultrastructural. The intensifying effects of reticulo-endothelial blockade on disseminated intravascular coagulation are well established (Lee, 1962).

Disseminated intravascular coagulation can affect the microcirculation in several ways. It can cause capillary or postcapillary obstruction purely by deposition of fibrin. Circulation of fibrinogen-fibrin complexes may determine a greater degree of red cell aggregation than fibrinogen itself and sludging is then worsened. The non-dissociable aggregates described in severe burns may be due to fibrin entanglement of the aggregates. One cannot but think in this connexion that it is fortunate that the endothelium of the venous side of the circulation, where aggregation is greater, is rich in plasminogen activator. There is also evidence (Bull, Rubenberg, Daciz, and Brain, 1968; Rubenberg, Regoeczi, Bull, Dacie, and Brain, 1968) that red cells can be deformed and fragmented during passage through fibrin meshworks. Here we have a potential vicious circle of defibrination, red cell injury starting a self-perpetuating process; microangiopathic haemolytic anaemia might be the result of such a mechanism. Finally, with severe disseminated intravascular coagulation, plasma fibrinogen levels can be greatly depleted and a haemorrhagic tendency can develop-a 'consumption coagulopathy'. However, the rate of replenishment of fibrinogen is rapid (Hardaway, Johnson, Elovitz, Houchin, Jenkins, Burns, and Jackson, 1964) and a single restricted episode of disseminated intravascular coagulation may not, unless severe and rapid, produce bleeding; but diminished liver function in shock may, on the other hand, cause failure of fibrinogent replenishment. Here again we have to deal with a balance of factors.

Disseminated intravascular coagulation, there. fore, adds to the shock picture the possibility of further microcirculatory obstruction and haemostatic defect.

Closely related to disseminated intravasculi coagulation, if not indeed the same, is endotoxte shock. This may be due to primary infection 18 endotoxin-producing organisms, mainly Grarfonegative bacilli. It may, however, be secondary to absorption of endotoxin from the gut devitalized by the shock state (Fine, 1965). Endotoxin 荡 small amounts is normally absorbed and is the detoxified by the reticuloendothelial syster, especially in the liver. In shock absorption cal be greater and detoxification reduced. How the endotoxin operates is far from clear. It may have effects on vascular smooth muscle directly or vä the nervous system, but in view of the strikipg similarities between the generalized Shwartzman reaction experimentally induced by carefuly spaced doses of endotoxin and disseminated intravascular coagulation, it seems reasonable believe that the special features of endotoxic shock are largely determined by an intravasculse coagulation mechanism. The term 'generalized Shwartzman reaction', useful though it has been in directing research to the field of defibrination and the role of the reticulo-endothelial syster, should, in my view, be discarded as too restrictiv.

\section{Conclusions}

The human body reacts to injury in a remarkabje way. If the principles of microcirculatory breakdown can be applied to each of the systems in in analysis of the clinical and biochemical featureges of shock we may hope increasingly to understagd shock and how to treat it. Such a systems approach is especially applicable in considering so-called 'shock organs'. Microcirculatory hyp perfusion of the myocardium, whether primary coronary inadequacy or secondary to shock, chrs determine central circulatory failure; pulmonary hypoperfusion may initiate the fatal pulmona insufficiency we see today in some patients who have been initially resuscitated with success; \&n other patients renal or adrenal features domin or there is a coagulation defect. We are orgy beginning to understand some of these interrelationships.

\section{References}

Brånemark, P-I. (1966). Intravital Microscopy. Its present stâtus and its potentialities. Med. biol. Ill., 16, 100-108.

Bond, T. P., Guest, M. M., and Derrick, J. R. (1968). High speed cinephotomicrography of the microcirculation in patients with haemolytic anaemia. In Proceedings of Internatiesal Conference on Microcirculation, Gothenburg. (Abstr.) 
Bull, B. S., Rubenberg, M. L., Dacie, J. V., and Brain, M. C. (1968). Microangiopathic haemolytic anaemia : mechanisms of red-cell fragmentation: in vitro studies. Brit. J. Haemat., $14,643-652$.

Chambers, D. R., and Monro, P. A. G. eds. (1969). Symposium on Techniques used in the Study of Microcirculation. British Microcirculation Society, Cambridge.

Fine, J. (1965). Shock and peripheral circulatory insufficiency. In Handbook of Physiology, Section 2, Circulation, edited by W. F. Hamilton, vol. 4, pp. 2037-2069. American Physiological Society, Washington, DC.

Florey, H. W., and Grant, L. H. (1961). Leucocyte migration from small blood vessels stimulated with ultraviolet light: an electron-microscope study. J. Path. Bact., 82, 13-17.

Gelin, L-E. (1956). Studies in anemia of injury. Acta chir. scand., Suppl. 210.

Hardaway, R. M., Johnson, D. G., Elovitz, M. J., Houchin, D. N., Jenkins, E. B., Burns, J. W., and Jackson, D. R. (1964) Studies on the fibrinogen replacement rate in dogs. Ann. Surg., 160, 825-838.

Hardaway, R. M. (1966). Syndromes of Disseminated Intravascular Coagulation. Thomas, Springfield, Ill.

Irwin, J. W., Chiu, H., and Nims, J. C. (1968). Biological emboli in passive anaphylaxis. Proceedings of International Conference on Microcirculation, Gothenburg. (Abstr.)

Knisely, M. H., Bloch, E. H., Eliot, T. S., and Warner, L. (1947). Sludged blood. Science, 106, 431-440.

Lee, L. (1962). Reticuloendothelial clearance of circulating fibrin in the pathogenesis of the generalised Shwartzman reaction. J. exp. Med., 115, 1065-1082.
McKay, D. G. (1964). Disseminated Intravascular Coagulation. An Intermediary Mechanism of Disease. Hoeber, New York.

Rhodin, J. A. G. (1967). The ultrastructure of mammalian arterioles and precapillary sphincters. J. Ultrastruct. Res., $18,181-223$.

Rhodin, J. A. G. (1968). Ultrastructure of mammalian venous capillaries, venules, and small collecting veins. J. Ultrastruct. Res., 25, 452-500.

Rubenberg, M. L., Regoeczi, E., Bull, B. S., Dacie, J. V., and Brain, M.C. (1968). Microangiopathic haemolytic anaemia; the experimental production of haemolysis and red-cell fragmentation by defibrination in vivo. Brit.J. Haemat., 14, 627.

Shepro, D., and Fulton, G. P. (eds). (1968). Microcirculation as Related to Shock. Academic Press, New York and London.

Stalker, A. L. (1964). Intravascular Erythrocyte Aggregation. Bibl. anat. (Basel), 4, 108-111.

Stalker, A. L. (1967). Histological changes produced by experimental erythrocyte aggregation. J. Path. Bact., 93, 203-212.

Stalker, A. L., Brown, L. J., Hall, J., and Blench, S. M. (1969). Studies on Experimental defibrination. I. Microcirculatory observations. Microvasc. Res., 1, 287-294.

Thorsén, G., and Hint, H. (1950). Aggregation, sedimentation, and intravascular sludging of erythrocytes. Acta chir scand., Suppl. 154.

Young, J. S., and Griffith, H. D. (1950). The dynamics of parenchymatous embolism in relation to the dissemination of malignant tumours. J. Path. Bact., 62, 293-311. 